\title{
TOXOPLASMOSIS IN SERBiA: tIME fOR AN ACTION PLAN ${ }^{1}$
}

DJURKOVIĆ-DJAKOVIĆ O.*, BOBIĆ B.* \& KLUN I.*

\section{Summary:}

Known for a century, Toxoplasma gondii has been studied in Serbia half this time, ever since the introduction of the Sabin-Feldman test at the Institute for Medical Research (IMR) in 1959. However, despite 50 years of continuous efforts, exact data on the frequency of acute clinical disease, acute infections in pregnancy and congenital infection in the offspring are still lacking, due to the vague regulatory provision that toxoplasmosis is subject to reporting "in case of epidemiological indications". It is, however, clear that the major Toxoplasma-induced public health issue in Serbia, like elsewhere in Europe, is congenital toxoplasmosis (CT). Continuous monitoring of particular patient groups showed a dramatic decrease in the prevalence of infection over the past two decades, and a consequently increased proportion of women susceptible to infection in pregnancy, suggesting a potential increase in the incidence of CT. Studies of risk factors for infection transmission have provided data to guide national health education campaigns. It is expected that the recent appointment of the National Reference Laboratory for Toxoplasmosis as the focal point for the collection of data from the primary level, will provide the means for accurate assessment of the measure of the problem, which is a prerequisite of an evidence-based nation-wide prevention program. In the meantime, health education of all pregnant women, focused at risk factors of major local significance, is advocated as a sound and financially sustainable option to reduce congenital toxoplasmosis.

KEY WORDS: toxoplasmosis, congenital toxoplasmosis, epidemiology, immunosuppression, prevention, public health, Serbia

T Toxoplasma gondii is one of the most successful parasites on Earth, infecting about one third of the global human population as well as all warm-blooded animals, birds and many cold-blooded species. Lately, it has been demonstrated in many marine organisms (Dubey, 2009).

\footnotetext{
* National Reference Laboratory for Toxoplasmosis, Serbian Centre for Parasitic Zoonoses, Institute for Medical Research, University of Belgrade, Dr Subotića 4, PO Box 102, 11129 Belgrade, Serbia. Correspondence: Dr Olgica Djurković-Djaković

Tel.: +381 112685788 - Fax +381 112643691

E- mail: olgicadj@imi.bg.ac.rs

${ }^{1}$ This article is based on an oral presentation given at the international conference "Parasitic zoonoses in present day Europe", Belgrade, 18-20 November 2009
}

Résumé : La toxoplasmose en Serbie: le temps du plan d'action Connue depuis un siècle, l'infection par Toxoplasma gondii est étudiée en Serbie depuis 1959 par I'Institut pour la Recherche Médicale avec l'introduction du test de Sabin-Feldman. Cependant, malgré 50 ans d'efforts continus, on manque de données précises sur la fréquence de la maladie aiguë, sur celle des infections survenant en cours de grossesse et sur celle de la contamination congénitale, car la déclaration de la maladie n'est obligatoire "qu'en cas de nécessité épidémiologique". Cependant, il est certain que le principal problème de santé publique en Serbie, comme ailleurs en Europe, concerne la toxoplasmose congénitale (TC). La suivi continu de groupes sélectionnés de patients a montré une diminution spectaculaire de la séroprévalence de l'infection au cours des deux dernières décennies, et par conséquent une proportion accrue de femmes susceptibles de contracter l'infection en cours de grossesse, laissant augurer une possible augmentation de l'incidence de la TC. Des études des facteurs de risque de transmission de l'infection ont apporté des données pour guider des campagnes d'hygiène au niveau national. On s'attend à ce que le Laboratoire de référence national pour la toxoplasmose, récemment créé, fournisse les éléments de bases nécessaires à une évaluation précise du problème, en vue de l'élaboration d'un programme national de prévention. En attendant, la préconisation d'une éducation sanitaire de toutes les femmes enceintes, axée sur les principaux facteurs de risque de contamination, est une option financièrement acceptable pour réduire la toxoplasmose congénitale.

MOTS CLÉS : toxoplasmose, toxoplasmose congénitale, épidémiologie, immunosuppression, prévention, santé publique, Serbie.

The recent centennial of the morphological recognition of Toxoplasma as a new species has presented a nice ocassion to summarize the knowns and the unknowns of this fascinating organism and the infection it causes, as well as future perspectives, and there have been publications and meetings to this effect around the world.

In Serbia, the history of the studies of Toxoplasma and toxoplasmosis dates back to the introduction of the Sabin-Feldman test by Dr Desanka Šibalić at the Institute for Medical Research (IMR) in 1959. Following a sabattical with Dr George Desmonts at the Institut de Puericulture in Paris, Dr Šibalić initiated seroepidemiological studies which provided the first data on the prevalence of toxoplasmosis in various population groups. Efforts in this area have been continuous all these fifty years. 
However, clinical research has been largely limited by the regulatory provision that toxoplasmosis is subject to reporting "in case of epidemiological indications", the vagueness of which resulted in the anecdotal nature of the data gathered, and a consequential lack of exact data on the frequency of acute clinical disease, acute infections in pregnancy and congenital infection in the offspring. Accordingly, studies are few, based on singlecentre patients, and are mostly limited to the efforts of the traditional laboratory at the Institute for Medical Research. Thus, insight into the measure of the problem is lower and we end up in a vicious circle: lack of research leading to lack of data which in turn leads into lack of knowledge among medical practitioners and the general public alike, resulting in further neglect of the problem. On the other hand, it is precisely such data that should represent the basis for a nation-wide evidence-based public health program for the prevention of toxoplasmosis. Accordingly, due to the lack of both such hard data and to the perennial lack of financial resources of the socialized public healthcare system, no systematic program for the prevention of congenital toxoplasmosis has ever been implemented in the country.

This paper reviews the current data on the epidemiology of toxoplasmosis in Serbia and addresses the steps to reduce the burden of the disease from a public health point of view.

\section{EPIDEMIOLOGY OF TOXOPLASMOSIS IN SERBIA}

\section{TOXOPLASMOSIS IN GENERATIVE AGE WOMEN IN SERBIA}

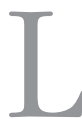

ong-term continuous epidemiological surveillance of toxoplasmosis in Serbia shows an intensive dynamics. A prevalence of around $50 \%$ registered during the first two decades of systematic investigation (1960-1980) (Šibalić et al., 1975; Šibalić, 1980) seems to have been followed by a sharp increase to an all-time high of up to $80 \%$ in the eighties (Djurković-Djaković, 1995; Bobić et al., 1998). This increase has not been fully explained, but it may be attributed at least in part to the changes in the serological tests used (introduction of commercial immunofluorescence and ELISA tests). Finally, as of the nineties up to the present, a gradual decrease has been continuously noted, to currently be no more than 30-35\% (Bobić et al., 2007). A decrease in the past two decades is not specific for Serbia; in all of Europe a decrease has been observed over the past decades, such as in France from $84 \%$ in 1965 to $67 \%$ in 1988 (Jeannel et al., 1988), to $54 \%$ in 1995 (Ancelle et al., 1995), and to $44 \%$ in 2003 (Berger et al., 2009), or closer to Serbia, in northern Greece, from $37 \%$ in 1984 to $24 \%$ in 2004 (Diza et al., 2005).

In Europe, significant variations have been shown to occur not only between countries but also within a given country, indicating local variations in the influence of epidemiological factors contributing to infection. Thus, European countries have implemented prevention programs in measure with the respective estimated risk of congenital toxoplasmosis. In France, where this risk was long known to be high, a national screening-inpregnancy program has been established since 1978, while for instance in Great Britain, based on a low infection incidence, only nation-wide health education of pregnant women was recommended (Henderson et al., 1984). In Serbia, a general screening-in-pregnancy program could never be afforded due to its cost vs. the financial capabilities of the public healthcare system. As a second-best alternative to general screening, we considered that insight into the risk factors of particular local significance could improve the quality of and the compliance with the hygienic and dietetic advice given to pregnant women as a preventive measure, as well as identify particular subpopulations at an increased risk of infection, who could then be selectively screened. To this effect, two studies of the risk factors for Toxoplasma infection in generative age women have been performed, which despite some differences generated similar results. The first one (Bobić et al., 1998), carried out between 1988 and 1991 in a series of 1,157 women from the Belgrade area, showed an overall prevalence of Toxoplasma infection of $77 \%$, but which was decreasing significantly over the study period $(\mathrm{p}<0.01)$. Factors associated with infection included age, undercooked meat consumption, and the year of entry into the study (understandably, since those were the precise years when the prevalence of infection was sharpy declining). In addition, in the youngest age group (below age 20) exposure to soil (farming, gardening) was significantly associated with infection. Since cats are the single source of Toxoplasma oocysts, this finding indicated cats were an epidemiologically significant source of environmental contamination in Belgrade. However, cat ownership itself was not associated with infection. A later study of risk factors for Toxoplasma infection involving a series of 2,936 women aged 15-49 years from throughout Serbia examined between 1988 and 1997 showed an overall prevalence of infection of $69 \%$, but with very wide variations both over time (decreasing from $86 \%$ in 1988 to $39 \%$ in 1997) and region (40-90\%) (Bobic et al., 2003). The risk of infection decreased from the north to the south, in line with the data on a northto-south decrease in infection rates in the whole region (from Hungary via Serbia to Greece) (Szenazi et al., 1997; Diza et al., 2005). Within Belgrade, the risk was 
higher in urban than in suburban zones. The single infection transmission factor shown to be a predictor of infection in the whole study group was undercooked meat consumption [relative risk $(\mathrm{RR})=1.6$, confidence interval $(\mathrm{CI})=1.2-2.1 \mathrm{l}$, while in the youngest population (aged 15-19) in women aged 15-19 exposure to soil was a strong predictor of infection $(\mathrm{RR}=10.3, \mathrm{CI}=2.7$ 38.6). Owning pet cats had no influence. Furthermore, while Toxoplasma infection was not associated with pathological pregnancies $(\mathrm{p}=0.51)$ in the whole study population, it was significantly associated with pathological pregnancies in women exposed to both undercooked meat consumption $(\mathrm{p}=0.009)$ and in those aged 15-19 in contact with soil ( $\mathrm{p}=0.022)$, as well as in women residing in highly urban communities $(\mathrm{p}=$ 0.048). These findings led us to conclude that the dramatic decrease in the prevalence of Toxoplasma infection over the nineties resulted in a rising proportion of women exposed to infection in pregnancy and consequently in an increased risk of congenital toxoplasmosis. Based on these data, and bearing in mind that the public health system could not afford a general screening-inpregnancy program, we proposed health education of all pregnant women in combination with serological testing of those exposed to predictors of infection as an epidemiologically sound and financially sustainable alternative (Bobić et al., 2003).

Finally, in a series of 765 women of generative age from throughout Serbia tested between 2001 and 2005, in which the prevalence of infection was $33 \%$, the infection risk factors were analyzed in a case-control manner in a group of 53 women with acute infection (cases) and a group of seronegative women matched for age and education level (controls) (Bobić et al., 2007). Undercooked meat consumption was the single predictor of infection in women with acute infection, with an 11-fold increased risk of infection in women who acknowledged consumption of undercooked meat.

Since, as reviewed above, undercooked meat consumption has repeatedly been shown to be the most significant predictor of Toxoplasma infection in Serbia, we performed an analysis of the significance of the consumption of particular meat types as sources of infection, which showed that of the meat types mostly consumed in Serbia, only consumption of beef influenced Toxoplasma infection rates (Bobić et al., 2007). Indirect evidence for the risk of undercooked meat consumption for Toxoplasma infection was also provided by a recent analysis of the seasonal distribution of acute toxoplasmosis in Serbia, which showed significant seasonality in the occurrence of acute toxoplasmosis in both symptomatic (recent lymphadenopathy) and asymptomatic patients (women tested for obstetric reasons), related to the seasons of the year (Bobic et $a l$, in press). In the symptomatic patients, acute infections occurred more often between October and March. Although more asymptomatic acute infections were diagnosed between February and July, low IgG avidity suggests infection had occurred within the previous trimester (between November and April). Undercooked meat consumption was shown as a risk factor for symptomatic infection in the October-March period $(\mathrm{OR}=7.67,95 \% \mathrm{CI}=1.61-36.45)$. These findings may be associated with the cultural habits of eating more meat in the winter period, particularly on the occassions of family festivities frequent at this time of the year, when whole young pigs and lambs are traditionally roasted.

\section{TOXOPLASMOSIS IN ANIMALS USED FOR HUMAN CONSUMPTION}

The above data prompted us to look into the frequency of toxoplasmosis in the most commonly used meat animals in our milieu. A cross-sectional survey on the seroprevalence of Toxoplasma infection in a representative sample of cattle, sheep and pigs from different regions of Serbia conducted between June 2002 - June 2003 showed a seroprevalence of $76.3 \%$ in cattle, $84.5 \%$ in sheep and $28.9 \%$ in pigs (Klun et al., 2006). Another study in sheep from a particular county (South Bačka in the northern province of Vojvodina) showed a much lower prevalence of only $36.7 \%$, but it involved a very small sample of 30 animals (Lalošević et al., 2006). Finally, a recent study showed a low prevalence of only $8.3 \%$ in market-weight pigs slaughtered at Belgrade abbatoirs (Klun et al., unpublished data). These data all show that meat animals present a significant reservoir of Toxoplasma infection for humans.

\section{TOXOPLASMOSIS AS A CAUSE OF PERINATAL INFECTION}

T loxoplasmosis has long been known as a major cause of perinatal morbidity. Acute infection in pregnancy may lead to fetal infection and subsequent fetal loss or birth of a manifestly or latently infected infant. In a study of the role of toxoplasmosis in the pathological outcome of pregnancy in Serbia (Djurković-Djaković, 1995), a series of 2,108 women with unsuccessful pregnancies, including 1,747 with spontaneous abortion, 187 with preterm delivery, 126 who delivered stillborn infants, and 48 whose offspring presented with clinical signs at birth, were tested for Toxoplasma IgG and IgM antibodies during pregnancy and/or up to six weeks after its termination. A nonpregnant group consisting of 157 women and a group of 568 women with a normal pregnancy were included as controls. Acute infection during pregnancy was associated with preterm delivery, stillbirth, and birth of infants with abnormal 
cranial volume, whereas there was no such association between acute toxoplasmosis and spontaneous abortion, or chronic infection and any of the pathological entities. In a study conducted between 1989 and 1993, in a geographically limited area (Timok region in East Serbia) a group of 2,778 pregnant women (17 \% of all pregnant women in the area during the examined period) were examined for Toxoplasma antibodies; $45.6 \%$ women were found seropositive, of which acute infection as determined by the presence of specific IgM antibodies was registered in $0.61 \%$. Furthermore, the results showed that Toxoplasma infection did not significantly affect the frequency of spontaneous abortions or of anomalies in the offspring at birth (Stojanović, 1998).

The burden of congenital toxoplasmosis (CT) varies widely between geographic regions, countries and even locales, depending on geographical, socioeconomic and cultural features. Although non-notification of cases of CT hampers exact data on the prevalence and incidence of CT, one attempt to provide some insight into the size of the problem of CT in the country was a retrospective analysis of the cases of acute toxoplasmosis in pregnancy and of CT in the neonate/infant diagnosed in our laboratory over the period 1994-1998 (DjurkovicDjakovic et al., 1998). The results showed an alarming discrepancy between the detection of acute infection in pregnancy and neonatal follow-up, as well as the occurrence of CT in infants born to mothers never tested for toxoplasmosis during pregnancy. This was further emphasized by the fact that only $2.5 \%$ women in this series were tested prior to pregnancy as a preventive measure. Thus, this data suggested the need for urgent implementation of prevention programs against this potentially detrimental yet preventable perinatal infection.

As throughout Europe, genotyping of the Toxoplasma strain in the few CT cases in which it has been performed showed the causative strains to be type 2 (Djurković-Djaković et al., 2006; Vujanić et al., 2009).

\section{OCULAR TOXOPLASMOSIS}

The issue has not been revisited in a long time, but data published in the eighties indicated toxoplasmosis as the leading cause of uveitis in Serbia (Šibalić et al., 1985). Toxoplasmic etiology was confirmed by local antibody production in even $13(59 \%)$ of the 22 uveitis patients in which aqueous humor was available. In four patients diagnosed with CT during the first year of life, chorioretinitis occurring at the age between 21 months and ten years was associated with the reappearance of Toxoplasma IgM antibodies (Šibalić et al., 1990). A more recent clinical survey (Risović, 2003) of 22 children with ocular CT showed episodes of reactivation in two during the study period of six years. Importantly, seven children had to be surgically treated due to low visual acuity $(<0.1)$ or strabism. These data all show that CT does occur in Serbia, which is often recognized only after the appearance of its late sequelae in the form of chorioretinitis.

\section{TOXOPLASMOSIS AS AN OPPORTUNISTIC INFECTION}

T The significance of Toxoplasma as an opportunistic agent has been recognized with the increase in the number of immunosuppressed individuals, such as patients with malignant and systemic diseases treated with immunosuppressive drugs, or in organ transplant recipients, but particularly with the outbreak of AIDS, as reviewed elsewhere (Djurkovic-Djakovic, 1998).

Once infected, the host acquires lifelong immunity induced by the persistence of the parasite in an encysted form. However, in the absence of immunological control, reactivation of a previously latent infection may occur, resulting in a wide clinical spectrum, predominantly within the central nervous system. Before the era of potent antiretroviral therapy, disease due to Toxoplasma was the leading cause of focal cerebral lesions in patients with AIDS (Luft \& Remington, 1992). The prevalence of latent toxoplasmosis in any given region indicates the local exposure to infection reactivation. One study to determine the frequency of and risk factors for toxoplasmic encephalitis (TE) in AIDS patients in Serbia (within the then-Yugoslavia), performed between 1991 and 1995, showed Toxoplasma IgG antibodies in 127 of the 288 AIDS patients (44.1\%) tested serologically (including all with neurological abnormalities) (Djurković-Djaković et al., 1997). A total of 31 patients developed TE, indicating an overall TE attack rate of $7.8 \%$. Of these, 29 TE episodes occurred in the Toxoplasma-seropositive patients, but two were registered in the seronegative ones. The cumulative incidence of TE in the seropositive patients was $32.7 \%$ for 60 months (30\% for 24 months). While not associated with age, sex or HIV transmission risk factor, the risk for TE increased with the decrease in the $\mathrm{CD}^{+} \mathrm{T}$ cell count $(\mathrm{RR}=0.276,95 \%, \mathrm{CI}=0.198-0.673, \mathrm{p}=0.0013)$, and was reduced in patients on systemic PCP prophylaxis $(\mathrm{RR}=0.222,95 \% \mathrm{CI}=0.068-0.642, \mathrm{p}=0.006)$. These results indicated that in areas of high exposure to Toxoplasma such as Serbia, serology for toxoplasmosis in HIV-positive patients should be performed early after the diagnosis of HIV infection, before it has progressed to AIDS. However, the situation has largely changed since the introduction of HAART in 1996, after which 
opportunistic infections including toxoplasmosis have become extremely rare (Jevtović et al., 2005).

\section{PREVENTION STRATEGIES}

T The global decrease in the prevalence of toxoplasmosis requires adjustment of the existing prevention strategies and many countries are currently rethinking the options. In the UK, due to a low estimated risk of infection, primary prevention of toxoplasmosis through avoidance of undercooked or cured meat has always been advocated rather than antenatal screening. On the other hand, few European countries, including France, Austria, Italy and Slovenia, have implemented screening in pregnancy programs. In Slovenia, a nonmandatory program introduced in 1981 became, due to an increased incidence of acute infections in pregnancy, mandatory in 1995 (Logar et al., 2002). In France, however, where a nation-wide state-funded screening in pregnancy program, with monthly screening of those seronegative, has been in motion for more than three decades, the decrease in the prevalence has recently led to proposals to reduce the frequency of serotesting, or to follow-up seronegative women only through monitoring of specific IgG antibodies (Ancelle et al., 2009). Whether antenatal treatment of women with presumed toxoplasmosis reduces congenital transmission of Toxoplasma is still under debate. As screening is expensive, it has been suggested for countries where screening programs have not yet been introduced, to not do so outside carefully controlled trials (Wallon et al., 1999). As part of the process of reform of public health services in Serbia, a network of reference laboratories for infectious diseases of public health interest was established by the Ministry of Health of Serbia in 2008. The appointed National Reference Laboratory for toxoplasmosis (NRLToxo) at the Institute for Medical Research has long been the single laboratory in ex-Yugoslavia to perform the diagnosis of toxoplasmosis, until commercial tests made it possible for a number of clinical and public health services, and more recently, laboratories in the private sector, to start performing toxoplasmosis serology. However, these provide only screening while NRLToxo is the single facility to perform specialized diagnostic procedures such as prenatal diagnosis including bioassay and molecular diagnosis of parasite DNA, or diagnosis in immunosuppressed individuals. The NRLToxo is envisaged to become the focal point for the collection of data from primary level laboratories, which will allow for accurate assessment of the size of the problem of toxoplasmosis in Serbia. Such data are necessary if prevention programs are to be planned. The remarkable decrease in Toxoplasma seroprevalence over the past two decades to the present $\sim 30 \%$ resulted in an increased proportion of women susceptible to infection in pregnancy. Moreover, in line with the global climate changes, the change of the climate in Serbia vs. one more similar to that in the more southern countries of Macedonia and Greece, and given the north-to-south decrease in infection rates in the region (from Hungary via Serbia to Greece) (Szenazi et al., 1997; Diza et al., 2005), a further decrease in the prevalence of Toxoplasma infection may be expected in Serbia. And actually, the NRLToxo currently witnesses an increasing number of acute cases and, subsequently, of congenital transmissions, reflecting the shortcomings of the healthcare system to identify all infections in pregnancy and intervene appropriately. What is now needed is an organizational algorithm indicating the responsibilities of the primary level laboratories vs. the NRLToxo as well as implementation of a quality assurance program. One step in the desired direction is the publication of the Good practice guide currently in preparation.

\section{CONCLUSIONS}

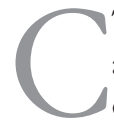

$\mathrm{T}$ is the major Toxoplasma-induced clinical entity and public health issue in Serbia. In view of the decrease in the prevalence of Toxoplasma infection which has occurred in Serbia over the past two decades, and the consequently increased proportion of women exposed to infection during pregnancy, implementation of a nation-wide program for the prevention of congenital toxoplasmosis is warranted. A prerequisite for such a program to be cost-effective is accurate assessment of the annual number of CT cases, expected to be provided by the recently appointed NRLToxo. In the meantime, health education of all pregnant women focusing particularly on the locally most significant risk factors for infection transmission, is a sound and financially sustainable option for the prevention of CT in Serbia.

\section{ACKNOWLEDGEMENTS}

The study was supported by grant No. 145002 from the Ministry of Science of Serbia.

\section{REFERENCES}

Ancelle T., Goulet V., Tirard-Fleury V., Baril L., Du Mazaubrun C., Thulliez P., Wcislo M. \& Carme B. La toxoplasmose chez la femme enceinte en France en 1995. Bulletin Épidémiologique Hebdomadaire, 1996, 51, 227-229.

Ancelle T., Yera H., Talabani H., Lebuisson A., Thulliez P. \& Dupouy-CAmet J. How can the cost of screening for toxoplasmosis during pregnancy be reduced? Rev. Epidemiol. Sante Publique, 2009, 57, 411-417. 
Berger F., Goulet V., Le Strat Y. \& Desenclos J.C. Toxoplasmosis among pregnant women in France: risk factors and change of prevalence between 1995 and 2003. Rev. Epidemiol. Sante Publique, 2009, 57, 241-248.

Bobić B., Jevremović I., Marinković J., Šibalić D. \& DJurkovićDJAKOVIĆ O. Risk factors for Toxoplasma infection in a reproductive age female population in the area of Belgrade (Yugoslavia). Eur. J. Epidemiol., 1998, 14, 605-610.

Bobić B., Nikolić A. \& DJuRKOvić-DjaKOvić O. Identification of risk factors for Toxoplasma gondii infection in Serbia as a basis of a program for prevention of congenital toxoplasmosis. Srp. Arh. Celok. Lek., 2003, 131, 162-167.

Bobić B., Nikolić A., Klun I., Vujanić M. \& Djurković-Djaković O. Undercooked meat consumption remains the major risk factor for Toxoplasma infection in Serbia. Parassitologia, 2007, 49, 227-230.

Bobić B., Klun I., Nikolić A., Vujanić M., Žıvković T., Ivović V. \& DJuRković-Djaković O. Seasonal variations in human Toxoplasma infection in Serbia. Vector Borne Zoonotic Dis., 2010, doi:10.1089/vbz.2009.0153.

Diza E., Frantzidou F., Souliou E., Arvanitidou M., Gioula G. \& ANTONIADIS A. Seroprevalence of Toxoplasma gondii in northern Greece during the last 20 years. Clin. Microbiol. Infect., 2005, 11, 719-723.

DjuRKOVIĆ-DjakOvić O. Toxoplasma infection and pathological outcome of pregnancy. Gynecol. Obstet. Invest., 1995, 40, 36-41.

Djurković-Djaković O., Bobić B., Vuković D., Marinković J. \& JevTović D. Risk for toxoplasmic encephalitis in AIDS patients in Yugoslavia. Int. J. Infect. Dis., 1997, 2, 74-78.

Djurković-Djaković O., Nikolić T., Ljubić A., Nikolić A., Bobić B., Stefanović Lj., Andjelković-Nikolić T. \& Dželetović A. Toxoplasmosis as a perinatal infection in Yugoslavia at the end of the millennium. Acta Infectol. Iugosl., 1998, 3, 123-128.

DjuRKOvić-DjaKović O. Toxoplasmosis and immunosuppression. Srp. Arh. Celok. Lek., 1998, 126, 197-203.

Djurković-Djaković O., Klun I., Khan A., Nikolić A., KnežEvićUŠAJ S., BOBIĆ B. \& SIBLEY D. A human origin type II strain of Toxoplasma gondii causing severe encephalitis in mice. Microbes Infect., 2006, 8, 2206-2212.

Henderson B.J., Beattie P.C., Hale E.G. \& Wright T. The evaluation of new services: possibilities for preventing congenital toxoplasmosis. Int. J. Epidemiol., 1984, 13, 65-72.

Jeannel D., Niel G., Costagliola D., Danis M., Traore B.M. \& Gentilini M. Epidemiology of toxoplasmosis among pregnant women in the Paris area. Int.J. Epidemiol., 1988, 17, 595-602.

Jevtović Dj., Salemović D., Ranin J., Pešić I., Žerjav S. \& DJuRKOVIĆ-DjaKović $\mathrm{O}$. The prevalence and risk of immune restoration disease in HIV-infected patients treated with highly active antiretroviral therapy. HIV Med., 2005, 6, 140-143.

Klun I., Djurković-Djaković O., Katić-Radivojević S. \& Nikolić A. Cross-sectional survey on Toxoplasma gondii infection in cattle, sheep and pigs in Serbia: seroprevalence and risk factors. Vet. Parasitol., 2006, 135, 121-131.
Lalošević V., LalošEvić D., Boboš S. \& Simin S. Seroprevalenca infekcije sa Toxoplasma gondii u regionu Srbobrana. Savr. Poljopriv., 2008, 67, 38-43.

Logar J., Petrovec M., Novak-Antolič Ž., Premru-Sršen T., ČIžMan M., Arnež M. \& Kraut A. Prevention of congenital toxoplasmosis in Slovenia by serological screening of pregnant women. Scand. J. Infect. Dis., 2002, 34, 201-204.

LuFt B.J. \& Remington J.S. Toxoplasmic encephalitis in AIDS. Clin. Infect. Dis., 1992, 15, 211-212.

Risović D. Oko i toksoplazmoza. Beograd. Defektol. Škola, 2003, 1, 148-152.

STOJANOVIĆ D. The effect of toxoplasmosis on occurrence of spontaneous abortions and anomalies in neonates in the Timok region. Vojnosanit. Pregl., 1998, 55, 151-159.

Szenasi Z., Ozsvar Z., Nagy E., Jeszenszky M., SZabó J., Gellén J., VÉGH M. \& Verhofstede C. Prevention of congenital toxoplasmosis in Szeged, Hungary. Int. J. Epidemiol., 1997, 26, 428-435.

Šibalić D., Radović M. \& Šulović V. Infection par Toxoplasma gondii pendant la grossesse et avant elle et les conséquences possibles sur le foetus, in: Proceedings of the Second European Multicolloquy of Parasitology. Petrović Z. (ed.), Trogir, 1975, 23-28.

Šibalić D. Études sur l'epidemiologie da la toxoplasmose en Serbia. Acta Parasitol. Iug., 1980, 11, 5-13.

Šibalić D., Blagojević M., Stanojević-Paović A. \& DjurkovićDJAKOvić O. Toxoplasmosis and ocular diseases. Investigation of the humoral immunologic response. Period. Biol., $1985,87,369-373$

Šibalić D., Djurković-Djaković O. \& Bobić B. Onset of ocular complications in congenital toxoplasmosis associated with immunoglobulin M antibodies to Toxoplasma gondii. Eur. J. Clin. Microbiol. Infect. Dis., 1990, 9, 671-674.

Vujanić M., Ivović V., Villena I., Klun I., Yera H., Bobić B., Nikolić A., Živković T. \& DJuRković-Djaković O. Molecular diagnosis of human Toxoplasma infection: increased sensitivity after bioassay. International Conference Parasitic Zoonoses in Present Day Europe. Focus on South-East, Belgrade, Serbia, 18-20.11.2009, Abstract book, p. 25.

Wallon M., Liou C., Garner P. \& Peyron F. Congenital toxoplasmosis: systematic review of evidence of efficacy of treatment in pregnancy. B.M.J., 1999, 318, 1511-1514.

Reçu le 6 mai 2010 Accepté le 17 juin 2010 